The 'Collaborative Personal Statement': a more inclusive method of data-gathering than audio recording interviews with vulnerable people Peter Williams ${ }^{\text {a* }}$

${ }^{a}$ Department of Information Studies, University College London, UK

Orchid ID: https://orcid.org/0000-0002-8628-239X

*corresponding author 


\section{The 'Collaborative Personal Statement': a more inclusive method of data-gathering than audio recording interviews with vulnerable people}

Inclusive research with people with learning disabilities often involves audiorecording interviews. However, although barely acknowledged in the literature, participants may not understand that every word recorded will be scrutinised forensically, from which possibly erroneous conclusions may be drawn. This paper describes an alternative method: the 'Collaborative Personal Statement' (CPS), which eschews the standard practice of making data gathering an unobtrusive, hidden audio-recording exercise in favour of dynamic interactive note-taking, in which participants' notes are read back to them, to be clarified, edited and augmented as part of interview sessions. The resulting narrative is also reviewed and finalised to produce the CPS. The paper argues that this obviates problems around, in particular, member checking, as participants are not burdened days later with the onerous task of examining and amending lengthy verbatim transcripts, often replete with various unflattering disfluencies. Also, the constant refining and clarification entailed in producing the CPS helps enable researchers to better explore, understand and analyse participant perspectives and meanings. To put the method into a research perspective, a case study of its use is outlined - the creation of a 'living electronic archive' relating the use and impact of mobile technology on the lives of people with learning disabilities.

Keywords: qualitative research, methods; recording interviews, inclusive research.

\section{Introduction}

Much emphasis is rightly placed on the value of inclusive, participatory research when undertaken with vulnerable cohorts such as people with learning disabilities. The term 'inclusive' refers to research in which participants are involved as co-designers, interviewers, data analysts and beneficiaries (Walmsley and Johnson, 2003; Williams, 1999). The concept of 'inclusive research' can 'be found predominantly in the field of learning disability research' (Nind, 2014: p3). 
Walmsley and Johnson, (2003) outline the characteristics that define inclusive research. These include making sure the 'research question, process and reports [are] accessible' (p64). Perhaps surprisingly, little consideration appears to have been given to the act of recording data accrued from participants. The issue is not simply 'how best to record data for the research', but 'how best to record data for the research in an inclusive manner'.

There is, unsurprisingly, a growing body of work on data gathering (rather than recording). Much of it (e.g. Brewster, 2004; Lloyd, Gatherer and Kalsy, 2006) concerns interviewing people with little or no speech. Even those who are able to communicate well may require special treatment (Sigstad and Garrels, 2018). Despite this attention to participant input, issues around inclusivity and understanding of data recording and reviewing have not been considered. This paper redresses this imbalance, making the case for an alternative and arguably more inclusive approach: the 'Collaborative Personal Statement' (CPS). It begins with an account of the case for audio-recording, highlights the minimal discussion there has been on using this method with vulnerable participants and explores why, for some participants, this approach may not be appropriate - principally in terms of inclusivity, but also, counter-intuitively, in terms of data capture and quality too. It then describes the CPS process, how it is being incorporated into a current research project, and the benefits accrued to the research participant and to researchers themselves.

\section{Audio-recording interviews}

Audio or video recordings of participant interviews are championed by qualitative researchers. The fall in the price of technology and the ever more discrete recording devices (such as a smartphone) are making such devices almost obligatory. Arguments for doing so are based primarily, and unsurprisingly, on the richness of data. Walliman, 
(2011: p100), for example, feels that recording is necessary 'in order to retain a full, uninterpreted record of what was said [without] rely[ing] on memory and repeated checking of what was said'. Lindlof and Taylor, (2017) point out that such recording preserves the paralinguistic aspect of speech (intonation, pauses and stress), and Braun and Clarke (2013:p92) mention that 'that it is difficult to develop rapport ... with a participant when we are looking down [at] a notebook rather than focusing on them'.

It is perhaps no surprise that many general works on research methods (such as Mills and Birks, 2014; Taylor Bogdan and DeVault, 2016) do not directly address issues around data recording in research with vulnerable people - although it is acknowledged that some people (not necessarily those considered to be vulnerable) may not feel comfortable being recorded. Interestingly, Braun and Clarke (2013) advise researchers to make it clear to participants that 'they are consenting to participate in an interview and consenting to being recorded' (p92, original emphasis). For these researchers, there does not even appear to be the scope for non-recorded participation.

Given the emphasis on inclusivity and co-researching with 'vulnerable' cohorts, it is surprising that issues around audio-capture (and analysis) of their contributions is omitted even in this literature. For example, neither Porter and Lacey's, (2005); nor Nind's (2014) influential volumes on the subject discuss the practice. In Cameron and Murphy's (2007) paper on obtaining informed consent from people with learning and communication disabilities the authors mention only that the research 'required the participants to be video recorded' (p114).

A rare example of consideration of the issue is that by Llewellyn (1995: p118) who pointed out that such practice may 'invade the privacy of the participant' by 'drawing attention to the person being interviewed, for example, in a coffee shop' (of course, affordable technology at the time was not small enough for the recording device 
to be unobtrusive). The author adds that, "no matter how relaxed participants become in the presence of a tape recorder, occasions do occur when information is withheld for privacy reasons or because of personal embarrassment'. Other than that, Llewellyn's case against audio-capture was exclusively about the needs of the researcher (e.g. 'the participant's speech or language style may be ... problematic when deciphering a recording' [p118]). The article also points out that 'valuable information is frequently shared when tape recording is not possible, for example, walking in the street, or after the machine is turned off'. Of course (although not mentioned) participants have to be made aware that such 'off the record' observations will themselves be considered as legitimate data and used in any analysis.

\section{The case against audio-recording}

There may be several reasons for not audio-capturing data. All of these are related to facilitating the spirit of inclusivity, and concern:

- Participant understanding of data analysis

- Lack of transcription or reporting sensitivity

- Member-checking discomfort (1): Confronting 'deficiencies'

- Member-checking discomfort (2): The burden of reviewing

\section{Participant understanding of data analysis}

Participants learning disabilities might not fully understand that everything they say is even being audio-recorded - and even less so that it will be forensically pored over, dissected, analysed and judged by researchers in their quest for insight and understanding. It is likely that even in studies whose participants may be more cognitively aware, they may not appreciate the extent to which their contributions are subject to scrutiny. This is because, despite consenting to be interviewed (whatever 
form that may take) there seem to be few attempts to describe the process of data analysis to participants, or the inferences or conclusions that are made from it - and thence seek consent to undertake such a process. In her account of interviewing women with learning disabilities, As McCarthy (1998: p143) reflects: 'it is one thing to consent to ... talking to an individual researcher, [but] it is quite another to consent to the hidden ... aspects of research, i.e. the researcher going away with your answers, analysing them, coming to conclusions about you and your situation (which you may not even understand, much less agree with) and then informing other people what they have discovered about you and people like you'. More succinctly, Swain, Heyman and Gillman (1998: p.21) note that 'the subject may have control over the release of raw data, but the researcher attaches a significance to these that untrained subjects may not apprehend'.

\section{Lack of transcription or reporting sensitivity}

Braun and Clarke, (2013: p163) advises qualitative researchers to:

'record all verbal utterances ... both actual words and non-semantic sounds - such as "erm", "err" [and] ..."mm"... Nothing should be "corrected" .... for example, if a participant says "dunno" it should not be transcribed as "don't know" ... the whole point of collecting spoken data is that we capture how people express themselves'.

It could be argued that the point of collecting data is not necessarily to find out how people express themselves, but to address a particular research question (in the present context, the impact on people's lives afforded by mobile technology). The trick is to make sure one understands exactly what someone means when they answer a question or make other observations. Of course, in some circumstances a completely verbatim rendition is necessary. Examples might be if one were carrying out a study of class and diction or regional language characteristics, or if there were some characteristic of the particular respondent that was required, such as to indicate membership of some sociological peer group or whatever; or if the 
utterance in question was ambiguous. Other than that, there does not seem to be any reason why it would be essential to undertake a phonetic transcription. It is interesting to note that, where Conference Proceedings talks or discussions are transcribed verbatim, this practice is never undertaken. As a random example, see Rippe, et al's (2017) panel discussion on 'Therapeutic Lifestyle Change Programs' which includes greetings and other salutations, but not a single mis-pronounced word or capture of a non-semantic sound!

Thus, it is argued here, there is an element of disrespect in the practice of including these linguistic elements - particularly considering the challenges some people have in selfexpression (and not only people with learning disabilities, of course). This may be true however sensitively the researcher treats the participants and however valuable the observations offered by participants is considered. An example is Clarke, Kitzinger and Potter's (2004) account of homophobic bullying, whose transcription extract (reflecting Clarke's own advice, cited above) of a mother reads 'the only thing we 'eard ...', and '[The]re weren't nobody responded to that.') Of course, using exact pronunciations and grammatical constructs may be important in, for example, socio-linguistic text analysis, but in this case there is no apparent reason for highlighting an inability or disinclination to pronounce particular letters or use appropriate grammar. The research focussed only on homophobic bullying, and the apparently poor diction was not the subject of comment. Some participants - or even academic readers - might find this documentation of a somewhat restricted language style rather belittling. This may be particularly true when framed within an extremely articulate and formal academic paper described as a 'discursive psychological analysis' in which accounts of bullying are considered 'implausible' by being 'discursively and rhetorically designed to deal with a heterosexist social/political context' (Clarke, Kitzinger and Potter, 2004: p531). Serving only to magnify the gulf between 'the academic' and 'the participant', the vocabulary used by the authors included such terms as 'extremitizing', 'corpus' and 'experiential certainty' (the latter juxtaposed with, and a label for, the participant's claim that 'we've 'eard it haven't we'). An argument will be made later for working with participants to, for example, render the grammar more standard where the meaning or emphasis does not alter. 


\section{Member-checking discomfort (1): Confronting 'deficiencies'}

The issue of the insensitivity of verbatim transcribing does not just refer to researchers' lack of sensitivity in reporting participant observations or a failure to aid selfexpression. At least as important is the discomfort that they may incur for participants who are suddenly presented with documentary evidence of how they sound in public. This occurs during the process known as member-checking, where the idea is for the participant to review the information they have given to the researcher - usually in an interview - and asked to check to see if they wish to add to their contribution or change any of it.

Member-checking will not be a problem for some people, but others might be both self-aware and sensitive enough to consider their efforts less than perfect. The literature illustrates this. In a refreshingly candid reflective paper, Carlson (2010) describes a series of negative reactions to transcripts presented to and read by her research participants. One of them found her interview transcript of an interview she had given to be 'so riddled with poor grammar that she did not know how I had ever been able to transcribe the tapes .... she was overcome with embarrassment and soon after withdrew from the study, apologizing that she had made a mess of my research'. (p1107). Forbat and Henderson (2005: pp. 1121-1122) also describe participant reaction to reading their interview transcripts. One interviewee said she was 'horrified by the number of times I said, "you know,"”, and another said of her transcript, 'a lot of this is rubbish'.

Considering that there is evidence to suggest that 'low self-esteem is common in people with learning disabilities' (Evans and Allez, 2018: p67) one might expect an equally negative reaction from those exposed to their verbatim comments. There is even a danger in this practice of upsetting those for whom the research is designed to support. 


\section{Member-checking discomfort (2): The burden of reviewing}

In addition to the above, there is the sheer burden of listening through an audiorecording or reading (or being read) a transcript, particularly as the practice is designed not simply as a reading (or listening) exercise, which may be taxing, but also to enable interviewees the opportunity to review, retract, re-articulate or otherwise modify content. Although, to an extent, problems of data review apply to that accrued from fieldnotes or in any other manner, they may be considered particularly appropriate in the case of audio-recorded interviews. This is primarily because of the indiscriminate, all-encompassing, sometimes (just like anyone else!) unguarded off-the-cuff or illexpressed content captured. Also, of course, transcripts are likely to be lengthy. 'Many' of Carlson's (ibid) 'were two to three dozen pages long' (p1106). Even the activity of listening may not facilitate feedback to a much greater degree. It may be difficult, especially if the audio is not particularly clear, to even determine intended thoughts or observations - much less to approve, amend or delete unsatisfactory passages.

Finally, there is often a significant time period between 'traditional' recorded interviews and the return of transcripts to interviewees, which may add an extra burden, in that what may have applied during the interview may no longer do so. This may be confusing when reviewing a transcript - although, of course, a time delay does offer the opportunity for interviewees to reflect on their contribution and modify it accordingly.

Despite possible difficulties, Brantlinger, et al, (2005), do suggest offering this kind of review with regard to a Special Educational Needs cohort, and as cited throughout this paper, there are a great number of instances of this practice - all, of course, designed to increase engagement and inclusivity. For example, Head et al's, (2018: p65) participants were interviewed twice, for between 30 and 90 minutes, the second time with a 'Key Support Person' (KSP) who helped with the interview. 
Participants were invited 'to listen to, amend and build on the responses of the KSP', possibly an onerous task, considering the interview lengths. By contrast, in Cithambaram, Duffy, and Courtney's (2018) study exploring the sensitive topic of people with learning disabilities' end-of-life care, 'most of the participants with ... asked the researcher to play back the record[ings]. They enjoyed listening to their voices'. They did not appear to have availed themselves of any opportunity to edit their contributions, however.

\section{Measures taken to minimise problems of recording participants}

Thus far, this paper has outlined the difficulties of using audio and, in particular, verbatim transcripts. Before turning to a discussion of the CPS, it is worth acknowledging existing efforts to minimise the problems outlined. One example is Nyhan and Flinn (2016) who, in their volume exploring an oral history of digital humanities, avoided member-checking problems by 'heavily' editing interview transcripts, partly to 'remove disfluencies and infelicities of speech', and also to delete repetitive narratives. They also published 'approved' transcripts “edited into a literary style (as opposed to a more natural verbatim style) to meet the concerns of some of the interviewees ...". Other researchers (e.g. Pestano, 2016; Harvey, 2016) show analyses of their interview transcripts, and Birt et al, (2016) returned both interview data and interpreted data. The latter consisted of 'a concise four-page report ... from the whole sample [with] spaces ... to encourage participant engagement. Each page summarized a theme from [the] results, and interpretations were contextualized using anonymized quotes to allow participants to comment on interview data'.

Other measures could be taken. These include putting a greater emphasis on the process of both recording and analysis in participant information sheets and consent forms, making reference to the recording as it is happening (not so much in terms of 
'don't forget, the voice recorder is running!' which might make participants feel uneasy, but more subtly: 'I hope the background noise isn't too loud on the recording'.

Such solutions appear to infer that audio-recording, even if edited, is somehow essential. The remainder of this paper challenges this view, by describing the Collaborative Participant Statement (CPS) method, entailing a form of dynamic and negotiated note-taking. It is best explained by reference to the research project outlined below within which it was developed, although the method could be used to capture interview data in any context, and not only with vulnerable people.

\section{The Collaborative Personal Statement (CPS)}

As mentioned above, the CPS method is being developed during the course of a research project, 'Digital Lives', exploring the use and impact of mobile digital technology by people with learning disabilities (see Williams, 2019a,b; Williams and Shekhar, 2019). The project is examining, in particular, their role in promoting selfexpression (Bunning, Heath and Minnion, 2009; Kwiatkowska et al, 2012); barriers encountered in negotiating technology (Williams, 2011) and how devices, interface usability and support may be improved.

Rather than to simply follow the standard procedure of gathering and analysing data, the project is working with participants to co-produce an accessible, annotated and hyperlinked e-archive of their experiences - password-protected and shared between participants, their supporters and researchers. Collections of the testimonies of people with learning disabilities are both rare (Keilty and Woodley 2013, and Deacon, 1974 being examples) and either in hardcopy or, even where electronic, static. The Open University (OU, 2015) and Trinity College, Dublin (NIID, 2015) both have modest amounts of material online, comprising of narratives of various individuals. However, there does not appear to be any resource that: 
- includes multimedia or links between contributors;

- is directly searchable;

- is dynamic.

Apart from concerns about audio-recording, that method did not, in any case, lend itself to the creation of what were to be written testimonies. However, researcher note-taking did not itself signify any greater involvement than letting an audiorecording and presenting the transcript to the interviewee. The resulting method became the collaborative creation of an interviewee statement, part of which - however much the participant wishes - becomes their archive entry. Data gathering begins with informal small-group discussions exploring issues related to people's experiences with, use of and opinions around mobile technology. The method is explained thus: "as we chat, I'll be taking notes - but I'll read them out as we go along, and you can add or take anything away. Sometimes I'll just listen, and you can tell me what to write afterwards". Thus, participants are constantly engaged and asked to confirm notes ("I just wrote this. Is it correct?") or for elaboration (“Can you tell me more about that?").

As an example, notes from one group were read back to participants, one of whom picked up the word 'joke', opining that he thought a more suitable word was 'meme', provoking a discussion around the meaning of these words. It thus gave a richer picture to both the researcher and participants around social media activity and also taught a couple of group members a new word.

Of course, researchers recording interviews may employ informal techniques that are comparable with methods formalised in the CPS process. These might include framing a question or topic in various ways or seeking clarification from the interviewee. The differences are that the researcher has to modify any transcript post- 
hoc to reflect the response the participant intended, and there is also a lack of immediate tangible output for the participant.

Returning to the CPS method, the session begins with general and then more specific questions, in a fairly unstructured manner but where necessary, steered back to the research topic (off-topic chats have included the relative merits of major football clubs, for example). In keeping with the method, the note-taking is a two-way process hence the name 'collaborative'. Participants are constantly informed of the notes taken, and asked if they are accurate or if there is any further observation any one wishes to make.

In a group environment, of course, one has to be careful not to allow a dominant figure to (quite literally!) dictate the proceedings, by making sure the voices of all are recorded ("What was that you said?" or even "What do you think?" to the least loquacious member of the group).

The process can be seen in Error! Reference source not found., Error! Reference source not found., where several iterations ('laps' of the circuit shown) are undertaken. 


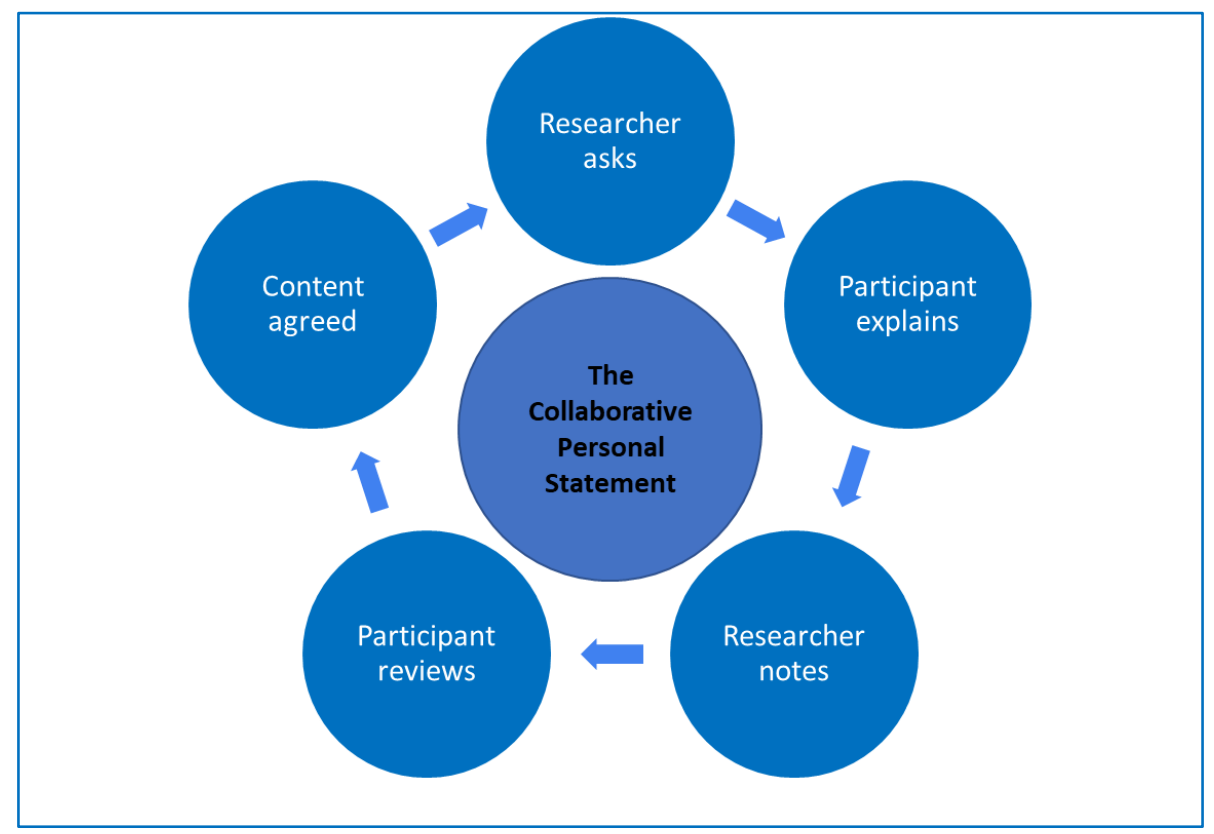

Figure 1: Interview process for the Collaborative Personal Statement

For the present project, individuals are asked after these sessions to chat with the researcher individually. Three overlapping activities are undertaken here, using the same collaborative technique:

- elaboration on group discussion contributions (important where others may have been more vociferous);

- demonstrations of device use (e.g. if they say they listen to music, they show how they access their collection). Thus, usability is also examined, both by observation and interview.

- reviewing notes taken during the activities above, augmenting or amending their observations as previously.

The resulting document constitutes the CPS.

For the present project, the additional step is taken of participants taking the CPS and editing it to include only the material desired on the Digital Lives archive. Thus, while the participant is making their comments, the process of creating the 
archive page is already beginning. To conclude the session, we read through the notes taken and the participant decides what to use in their archive entry. In some cases, the prospect of acquiring their own page provides an incentive to supplement the existing text. The archive also supports photos, and for those who choose to use this feature, further content may be generated with discussion around these.

The final stage of the activity is to ask participants to have a final read-through (usually the document will be less than a page long) and make one final edit. This practice fulfils a major requirement in Tong, Sainsbury and Craig's (2007: p.356) checklist for reporting qualitative interviews: 'ensuring that the participants' own meanings and perspectives are represented and not curtailed by the researchers' own agenda and knowledge'. As Creswell and Creswell (2018: p180) point out, 'in the qualitative research process, researchers focus on the meaning the participants hold ... not the meaning the researchers bring to the research.'

This focus on participant meanings is strongly reflected in, for example, the Interpretative Phenomenological Approach (IPA), where 'the researcher gains an understanding of [some] phenomen[on] from the participant's perspective ... [and is] only interested in the experience and meaning held by the participants', (Darragh et al., 2017: online). To enable this, IPA eschews a structured interview format for one where 'the interview may enter an area that had not been predicted by the investigator but which is extremely pertinent to ... [a research] project's overall question' (Smith and Osborn, 2008: p233). As with the final review stage of the CPS, the emphasis on capturing unprompted observations means that 'such contributions are likely to be of especial importance for [the participant]' (p233).

Unlike CPS, however, IPA also offers also a specific method to analyse, in addition to capture, these data. Smith and Osborn (2008: p234) explain that 'one begins 
[an IPA] with the first transcript and engages in a systematic search for themes ... in it. One then attempts to forge .... Having done this for the first case, one moves to the second ...' By contrast, the element of analysis in the CPS is limited to taking findings back to participants and peers for their further insights. This contribution to the data analysis is one of the proposed benefits of the CPS, to which this paper now turns.

\section{Benefits of the CPS method}

The construction of a CPS using the method outlined above, accrues a number of benefits to the participants, both relative to the practice of audio-recording interviews and in other ways. The former include:

\section{Participant understanding of data analysis}

The CPS cannot completely obviate this problem, but at least with the constant confirmation of words and intended meanings that are an integral part of the method, plus the final statement 'member check' where the participant can verify or amend their contribution to determine the exact meaning they wished to convey. They therefore become agents, at least in a preliminary analysis of their input, and thus exercise some control over the process.

Member-checking - taking overall findings back to participants or their peers - is quite common with other methods, of course, but the benefit of adopting this practice with CPSs lie in their form. First, 'member-checkers' do not have to wade through long audio recordings or transcripts. The statements are short and accessible - written by their peers and shorn of extraneous 'infelicities' of speech.

Second, where the checkers are also participants in the same project, they will have also produced CPSs and will therefore be familiar with the method. With the Digital Lives project, for example, member-checking participants were asked for their 
view on a number of CPSs which included negative comments that had been made by their peers. These included:

- "I don't have a phone because I am afraid of leaving it somewhere!"

- "I don't have a phone, it will get lost."

- "I don't walk around with [my tablet] - it is too valuable."

- "On the Internet you can get a virus. That gets on the phone and can break it." A group conversation around these phrases accrued more data, on the lines of the responsibility felt in owning and carrying a mobile device, with the researcher pointing out that the member-checkers had been able to provide an explanation for these statements.

\section{Lack of transcription sensitivity}

The data collection respects the views of the participants themselves - unintended asides or ill-considered comments that might not reflect actual views are edited out or not recorded in the first place. It is true, of course, that such 'unguarded' comments are a truer reflection of participant views. However, even with audio-recording, the membercheck process allows participants to retract data - and in any case, to be truly participatory and inclusive, it is morally incumbent upon researchers to respect the views of participants as they wish them to be represented. Related to this point, Dorothy Atkinson (2010), in her work helping people with learning disabilities narrate their autobiographies, describes her participants as 'expert witnesses', and argues that despite problems in articulation, they know more about their own experiences than professionals or academics (Atkinson, 2010). Grant and Ramcharan (2009: p29), in similar vein, describe this as being 'expert by experience'. 


\section{Member-checking discomfort (1): Confronting 'deficiencies'}

Following from the above, the arguments advising against the loss of paralinguistic and anacoluthic data can be turned on their head, by putting the case for choosing to eliminate these. It could be argued that declining to capture audio and negotiating what to write instead, maintains the dignity of participants more than the capture of every last placeholder (e.g. 'thingy') or pause filler ('err...'), and avoids their possible discomfiture in listening to or seeing their words rendered verbatim with the extraneous elements mentioned above. Indeed, far from feeling uncomfortable or embarrassed, participants have the satisfaction of actually creating and seeing their research contributions. For the present project, they are even able to compare them with those of their peers.

\section{Member-checking discomfort (2): The burden of reviewing}

A form of member-checking is undertaken during the course of the fieldwork, and in very small, manageable 'chunks' - although the full contribution of the participant is also reviewed to finalise the CPS. This method is far less of a cognitive burden on participants than would be the case in working through a dense verbatim transcript, post-hoc. Of course, it also gives the researcher the opportunity to seek clarifications and elicit more information.

There other advantages of the CPS for participants. These include:

\section{Insights for participants into their own views}

This has been claimed for the practice of returning audio transcriptions for participants. Forbat and Henderson (2005: p1120) write of a transcription returned for 'memberchecking', as being 'of a different ontological order from that of the spoken interview ... [by] offer[ing] speakers opportunities to consider their views and stories in a form 
that they perhaps would not have done without taking part in the research'. The practice of CPS would do the same. Indeed, by reviewing, rearticulating and reconsidering their spoken observations as interviews progress, the process is more dynamic and less burdensome - in addition to reflecting upon the finished CPS later.

\section{Data sharing between participants}

This advantage applies specifically, of course, where the CPS is disseminated, as with the Digital Lives' electronic archive of experiences which allows participants to read and reflect on the entries of their peers. It thus also gives the opportunity to, as Harvey (2015, as cited in Birt et al, 2016: p1805) states, 'give participants an opportunity to consider whether any of the experiences or perceptions of others also applied to them'. Thus, participants are able to look at their own views and experiences within a wider context, but also for academic research also, as if the researcher (gently) probes them on their reaction to peers' contributions, further data emerges to inform the research, as mentioned above. Such an activity has roots in a grounded theory approach (Glaser and Strauss, 1967).

There are also specific benefits in the method for researchers too, in addition to those such as the greater inclusivity afforded by the method, or the rather more practical benefit of not having to transcribe interviews. These include:

\section{Minimising fieldnote-only data loss}

Loss of data through only taking fieldnotes is avoided. Studies show that $50 \%$ to $66 \%$ of data is lost when using this method alone (Tessier, 2012). Of course, this method does result in some data loss, but this is considered to be a justifiable sacrifice, considering the general ethos of inclusive research and ensuring the dignity of participants. 


\section{Arguments against the CPS approach}

Arguments against the approach include:

- Loss of own voice;

- Including socially (or even legally) unacceptable views;

- Use of material not chosen for the CPS.

\section{Loss of own voice}

This is the only issue which relates solely to the method of data gathering rather than to the dissemination or display of the CPS. With regard for respect for the 'voice' of the participants, one problem is that of so-called 'acquiescence bias'. This is the practice of agreeing with the researcher, as a person of authority, whatever the question or issue (Sigelman et al. 1981). In the current context, this would manifest itself where the researcher rephrased a comment and then asked if the rephrasing still reflected participant views (with the response being 'yes', regardless). One could argue that it is essential to use the words of the participants themselves, even if without word repetition or non-semantic utterances. However, there are examples where a meaning may be very clear, whether expressed in incorrect or correct forms of English. For example, the phrase "I don't know nothing about computers", clearly means the same as "I don't know anything about computers". Here, one could say that it is doing a disservice to participants to ignore these small errors - at least when they are to be committed to the written word.

This is not to denigrate participants, and does not deny that a 'restricted code' of language 'contains a vast potential of meanings [and] ... [and] should not be disvalued.' (Bernstein, 1971: p152). However, in establishments visited (and in other similar locations, of course) by the researcher, support staff work tirelessly to help the people 
they support develop literacy and other skills. Surely, within a declared 'inclusive' paradigm, researchers too can play a very small role in efforts to aid the self-expression of those from whom they are seeking information.

\section{Including socially (or even legally) unacceptable views in the CPS}

This problem relates specifically to material that may be shared, such as with the Digital Lives archive. Obvious examples might be homophobic, racist or otherwise discriminatory comments - but equally, they may discuss acquaintances, colleagues or supporters in derogatory terms. Again, this situation suggests that an educative element to the CPS is appropriate, around what is unacceptable in public discourse. Where the involvement with the participant may be long, this issue could be taken further, in collaboration with support workers, family etc. ${ }^{1}$

\section{Use of material not chosen for the CPS}

This issue also arises only where a CPS is for dissemination. All material produced during research sessions constitute research data, of course - not just those chosen by participants for public consumption. In fact, comments that are not appropriate for public display may provide the most valuable insights. It is therefore of great importance where that element is present, to convey that all material will be considered in the research, not just an edited version for others to see. On the other hand, where participants have edited or otherwise modified their statements to arrive at what they regard as a true record of their views, it is an ethical requirement on the part of

\footnotetext{
${ }^{1}$ The US organisation Teaching Tolerance has some excellent teaching materials on inclusion and acceptance: https://www.tolerance.org/
} 
researchers to ignore original text. Trust in the researcher will be broken, and claims of inclusivity in the research unsustainable.

\section{Conclusion}

The CPS method described in this paper arose out a concern that, despite its apparent ubiquity, vulnerable research participants may not be aware of the consequences of having every word they utter audio-recorded or, indeed, not fully understand what the process means - despite care being taken to obtain 'informed' consent. This concern led the author to both take interview notes and, by contrast to recommended practice, make this data gathering as obvious as possible. It is argued that the constant referral back to the participants to confirm, clarify, augment or otherwise modify their observations confers many advantages over the standard practice of audio-recording. These include having a greater understanding of, and input to, the data analysis process; greater researcher sensitivity towards recording the data; participants not being burdened with the transcript or audio of an hour's conversation to negotiate, confronting their linguistic 'inadequacies'. For the researcher, the method avoids the usual problem of losing data through only taking fieldnotes, and also, the data gathered is easier to reuse. At the heart of the method, however, is the effort to afford a voice, a sense of contribution and dignity to those who still face 'societal-wide exclusion and discrimination' (Simplican et al, 2015: p22). If nothing else, hopefully the method contributes to the debate around how best to meet the aspirations that all researchers (and others) have around involvement, inclusion and empowerment.

\section{Funding details}


This work was supported by the British Academy Post-doctoral Fellowship scheme under Grant number pf160147.

\section{Acknowledgements}

This study is part of a research project generously funded by The British Academy as a Post-doctoral Fellowship. The author would also like to thank his steering group, Prof. Barrie Gunter, Dr Andrew MacFarlane, Dr Mina Vasalou, Dr Rob Miller and (during Rob's sabbatical) Prof. Elizabeth Shepherd, for their constant invaluable help and advice. Thanks, too, to all the participants and supporters at the various sites where the research was undertaken.

\section{References}

Atkinson, D. 2010 Narratives and people with Learning Disabilities in Grant, G., Ramcharam, P., Flynn, M. and M. Richardson Learning disability: a lifecycle approach Milton Keynes: Open University pp.7-18

Bernstein, B. 1971. Class, Codes and Control: Theoretical Studies Towards a Sociology of Language. London: Routledge \& Kegan Paul

Birt, L., Scott, S., Cavers, D., Campbell, C., and F. Walter, 2016. Member Checking: A Tool to Enhance Trustworthiness or Merely a Nod to Validation? Qualitative Health Research, 26(13) pp.1802-1811.

Brantlinger, E., Jimenez, R., Klingner, J., Pugach, M. and V. Richardson. 2005.

Qualitative Studies in Special Education. Exceptional Children, 71(2),pp.195-207. Braun, V. and V. Clarke. 2013. Successful Qualitative Research London: Sage Brewster, S. 2004 Putting words into their mouths? Interviewing people with learning disabilities and little/no speech British Journal of Learning Disabilities 32(4) pp.166-69

Bunning K., Heath B. and A. Minnion. 2009 Communication and empowerment: a place for rich and multiple media? Journal of Applied Research in Intellectual Disabilities, 22(4) pp.370-379. 
Cameron, L. and J. Murphy. 2007. Obtaining consent to participate in research: the issues involved in including people with a range of learning and communication disabilities. British Journal of Learning Disabilities, 35(2), pp.113-120.

Carlson, J. 2010. Avoiding Traps in Member Checking. Qualitative Report, 15(5) pp.1102-1113.

Cithambaram, K., Duffy, M. and E. Courtney. 2018 End-of-life care research on people with intellectual disabilities: Challenges for proactive inclusion in an Irish context British Journal of Learning Disabilities 47(2). Pp.70-76

Clarke, V., Kitzinger, C., and J. Potter. 2004. 'Kids are just cruel anyway': Lesbian and gay parents' talk about homophobic bullying. British Journal of Social Psychology, 43, pp.531-550.

Cresswell, J. and J. Cresswell. 2018 Research design London: Sage

Darragh, J., Reynolds, L., Ellison, C. and M. Bellon. 2017. Let's talk about sex: How people with intellectual disability in Australia engage with online social media and intimate relationships. Cyberpsychology: Journal of Psychosocial Research on Cyberspace, 11(1), article 9.http://dx.doi.org/10.5817/CP2017-1-9 (accessed 24.04.19) Deacon, J. 1974 Tongue Tied London: Mencap.

Evans, L. and K. Allez. 2018 Cognitive behaviour therapy for low self-esteem in a person with a learning disability: a case study, Advances in Mental Health and Intellectual Disabilities, 12(2), pp.67-76.

Forbat, L. and J. Henderson. 2005. Theoretical and Practical Reflections on Sharing Transcripts With Participants. Qualitative Health Research, 15(8) pp.1114-1128. Glaser, B., and A. Strauss. 1967 The Discovery of Grounded Theory: Strategies for Qualitative Research Chicago: Aldine 
Grant, G. and P. Ramcharan. 2007 Valuing people and research: The learning disability research initiative London: The Department of Health

Harvey, L. 2015. Beyond member-checking: A dialogic approach to the research interview. International Journal of Research \& Method in Education, 38, pp.23-38 Head, A., Ellis-Caird, H., Rhodes, L. and K. Parkinson. 2018. Transforming Identities through Transforming Care: How People with Learning Disabilities Experience Moving out of Hospital. British Journal of Learning Disabilities, 46(1), pp.64-70.

Keilty, T. and K. Woodley. 2013 No going back: forgotten voices from Prudhoe Hospital, Sheffield: Centre for Welfare Reform Available online at: https://www.centreforwelfarereform.org/uploads/attachment/441/no-going-back.pdf (accessed 22.01.19)

Knox, S.and A. Burkard. 2009. Qualitative research interviews. Psychotherapy Research, 19(4-5) pp.566-575

Kwiatkowska, G., Tröbinger, T., Bäck, K. and P. Williams, P. 2012 Multimedia advocacy: a new way of self expression and communication for people with intellectual disabilities in Miesenberger, K., Karshmer, A., Penaz, P. and W. Zagler. (Eds.): Computers Helping People with Special Needs - 13th International Conference, ICCHP 2012, Linz, Austria, July 11-13, 2012, Proceedings, Part II. Lecture Notes in Computer Science 7383 Verlag Berlin, Heidelberg: Springer pp. 361-368 Lindlof, T., and B. Taylor. 2017 Qualitative Communication Research Methods London: Sage

Llewellyn, G. 1995 Qualitative research with people with intellectual disability Occupational Therapy International 2(2) pp.108-127 
Lloyd, V., Gatherer, A. and S. Kalsy. 2006. Conducting Qualitative Interview Research with People with Expressive Language Difficulties. Qualitative Health Research 16 (10): 1386-1404.

McCarthy, M. 1998. Interviewing People with Learning Disabilities about Sensitive Topics: A Discussion of Ethical Issues. British Journal of Learning Disabilities, 26(4), $140-145$.

Mills, J., Birks, M. 2014. Qualitative Methodology: A Practical Guide. 55 City Road: SAGE Publications.

Nind, M. 2014 What is inclusive research? London: Bloomsbury Nyhan, J. and A. Flinn. 2016 Introduction in Nyhan, J. and A. Flinn. 2016 Computation and the Humanities: towards an Oral History of Digital Humanities Belin: Springer International

OU (Open University). 2015 Social History of Learning Disability: Life stories Available at: http://www.open.ac.uk/health-and-social-care/research/shld/resources-andpublications/life-stories (Accessed 02.07.18)

Pestano, C. 2015. Exploring the Self-concept of Adults with Mild Learning Disabilities. British Journal of Learning Disabilities, 43(1), pp.16-23 Porter, J. and P. Lacey. 2005. Researching learning difficulties a guide for practitioners. London ; Thousand Oaks.

Rippe, J., Campanile, G., Diehl, H., Gunier, C., Kostohryz, T., Longjohn, M., . . . Bonnet, J. (2017). American College of Lifestyle Medicine Expert Panel Discussion: Implementing Intensive Therapeutic Lifestyle Change Programs. American Journal of Lifestyle Medicine, 11(5) pp.375-386 
Sigelman, C., Budd, E., Spanhel, C., and C. Schoenrock. 1981. When in doubt, say yes: Acquiescence in interviews with mentally retarded persons Mental Retardation 19(2) pp53-58

Sigstad, H. and V. Garrels. 2018 Facilitating qualitative research interviews for respondents with intellectual disability. European Journal of Special Needs Education, 33(5), 692-706.

Simplican, S., Leader, G., Kosciulek, J. and M. Leahy. 2015 Defining social inclusion of people with intellectual and developmental disabilities: An ecological model of social networks and community participation, Research in Developmental Disabilities 38(1) pp.18-29

Smith, J., and Osborn, M. (2008) Interpretative Phenomenological Analysis. In Breakwell, G. Doing Social Psychology Research. British Psychological Society and Blackwell pp. 229-254.

Swain, J., Heyman, B. and M. Gillman. 1998 Public research, private concerns: Ethical issues in the use of open-ended interviews with people who have learning disabilities. Disability and Society 13 (1), 21-36.

Taylor, S., Bogdan, R. and M. DeVault. 2016. Introduction to qualitative research methods : A guidebook and resource Hoboken, New Jersey : John Wiley \& Sons, Inc.: Fourth edition

Tessier, S. 2012 From Field Notes, to Transcripts, to Tape Recordings: Evolution or combination International Journal of Qualitative Methods 11(4) pp.446-460

Tong, A., Sainsbury, P. and J. Craig. 2007. Consolidated criteria for reporting qualitative research (COREQ): A 32-item checklist for interviews and focus groups. International Journal for Quality in Health Care, 19 pp.349-357 Walliman, N. 2011. Research Methods: The Basics. London: Routledge 
Walmsley, J. and K. Johnson. 2003. Inclusive Research with People with Learning Disabilities: Past, Present and Futures London: Jessica Kingsley

Williams, P. 2011. Barriers to the Creation and Use of an Accessible Web Portal for People with Learning Disabilities International Journal of Education 3(2) e21

Available at: http://www.macrothink.org/journal/index.php/ije/article/view/1283 (accessed 13.09.16)

Williams, P. 2019a. Facebook use by people with learning disabilities: The case for facilitated, guided autonomy. New Trends and Issues Proceedings on Humanities and Social Sciences, 6(5), pp.99-108.

Williams, P. 2019b. Smartphones and people with learning disabilities: self-reported barriers to effective usage. Proceedings of the International Academic Conference on Teaching, Learning and E-learning in Budapest (IAC-TLEl), Budapest, Hungary, on March 15 -16, 2019. pp.7-16

Williams. P. and Shekhar, S. 2019 Mobile devices and people with learning disabilities: a literature review International Journal of Computer Science and Mobile Computing 8(2) pp.34-43

Williams, V. 1999. Researching together British Journal of Learning Disabilities 27(2) pp. $48-51$ 